\title{
ANALYTICAL PROCEDURE FOR SEISMIC ASSESSMENT OF MASONRY BUILDINGS WITH HISTORICAL VALUE
}

\author{
Stylianos J. Pardalopoulos ${ }^{1}$, Maria Th. Kontari ${ }^{1}$, Stavroula J. Pantazopoulou ${ }^{2,1}$ \\ ${ }^{1}$ Demokritus University of Thrace \\ Dept. of Civil Engineering, Xanthi, Greece \\ spardalo@civil.duth.gr, marikont@civil.duth.gr \\ ${ }^{2}$ University of Cyprus \\ Dept. of Civil Engineering, Nicosia, Cyprus \\ pantaz@ucy.ac.cy
}

Keywords: Masonry buildings, Seismic assessment, Heritage buildings

\begin{abstract}
Today, about 60 years after the proliferation of reinforced concrete in urban construction, structures that are classified as heritage buildings carrying a significant value from the past belong mostly to the class of unreinforced load-bearing masonry construction (URM), dating back to the 19th and early 20th Century. Extending current practices for seismic assessment to these buildings is not straightforward, as, in contrast with conventional frame structures, they are characterised by distributed stiffness and mass and poor diaphragm action. Interventions are often restricted by international treaties for non-invasiveness and reversibility of the intervention - given the practical requirements for the buildings' intended reuse. Poor understanding of the mechanics of masonry and the inherent brittleness of the material further compounds the uncertainties in analytical methods used for assessment and rehabilitation. Simplified procedures that produce dependable results for estimating seismic demand for this class of structures are a primary objective of this paper. In a displacementbased context, requirements are determined from the spectral acceleration and displacement at the end of the constant acceleration range, $T_{c}$, in light of the fact that these structures seldom exceed two storeys in height above ground. Displacement demand at the reference point is then distributed through the structure following a simplified estimate of the fundamental mode of vibration; this is calculated in each of the two principal directions of the building in plan, by applying a lateral load distribution analogous to its mass distribution. The intensity of local demand and likelihood of damage are estimated as relative drift ratios, in plan and in height, of the masonry piers of the structure. A case study of two neoclassical buildings damaged in the 1978 earthquake in Thessaloniki are used as a point of reference for illustration of concepts - results are correlated based on their ability to reproduce the patterns of damage observed during post-earthquake reconnaissance evaluations of the building.
\end{abstract}




\section{INTRODUCTION}

Historic and cultural buildings of the $19^{\text {th }}$ and $20^{\text {th }}$ Century are a significant part of the built environment in many cities across Europe. Having a lifetime of more than a hundred years, load-bearing masonry buildings of this class are a living part of the European history and as such, they are protected by international treaties and organizations. Over the several decades of their service life, most of those buildings have suffered from structural damages of different severity level, especially in countries of the Mediterranean basin with high seismicity. Yet, even today they remain in good condition, being operational in many cases (Fig. 1). Due to those buildings' historical importance and their significance as examples of an architectural school of thought, an increasing interest for their rehabilitation has recently emerged, often regulated by international treaties for noninvasiveness and reversibility of the intervention combined with the practical requirements for the buildings' modern day intended reuse.
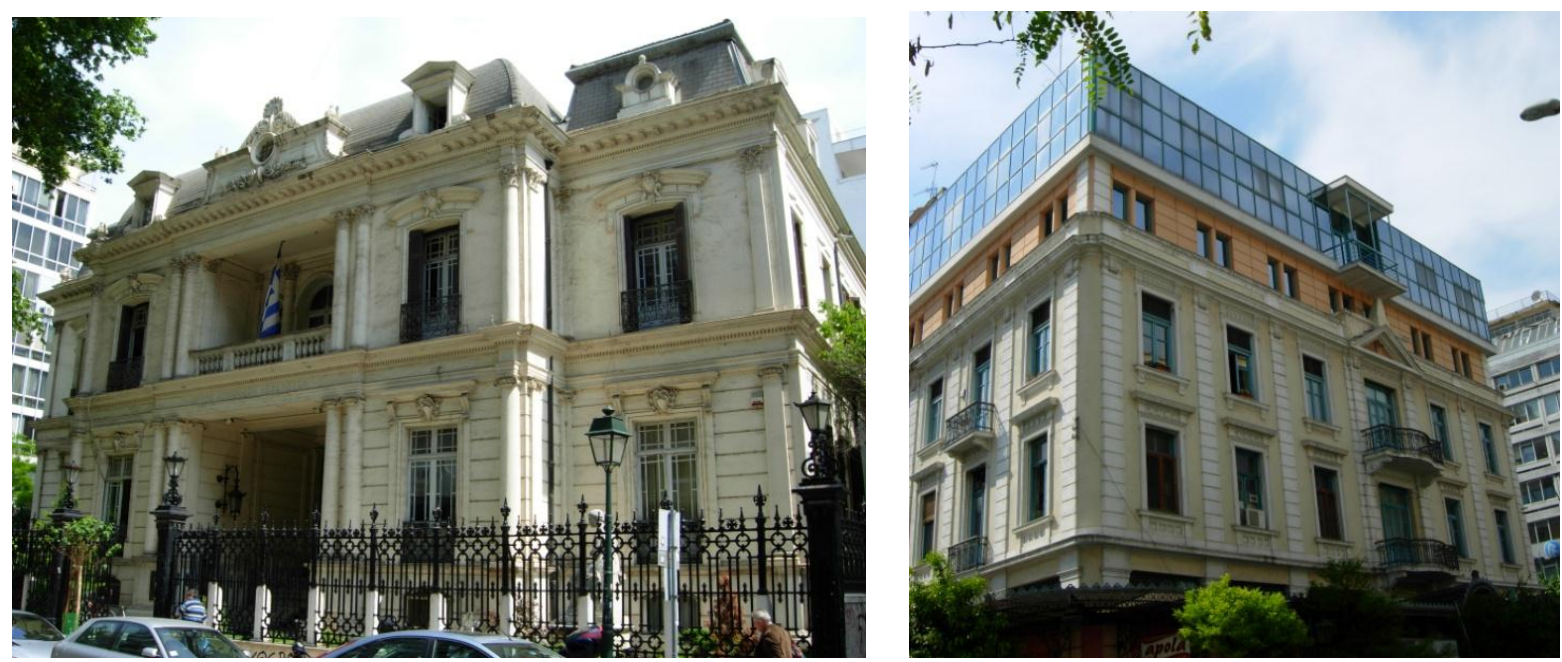

Figure 1: Heritage buildings of the $20^{\text {th }}$ Century located in the center of Thessaloniki, Greece.

\section{PRACTICAL DIFFICULTIES IN COMPUTER MODELLING OF URM STRUCTURES}

Eurocode 8-III [1] provides guidance for assessment of existing structures, which rides on analytical estimations of seismic demand that are calculated from a number of analytical alternative representations of the structure. Those representations are ranging from equivalent single degree of freedom systems to detailed three-dimensional modeling of the geometrical details with consideration of the regions of nonlinearity; the seismic hazard may also be represented simply, through an acceleration spectrum or through an acceleration time history which requires step by step integration through time; the spectral representation of the seismic hazard lends itself to modal superposition, provided that the structural model is linearly elastic, or to "performance-point evaluation" if a "static" pushover curve may be independently established for the structural system. These two general options regarding choices of representation of the structural and the loading degrees of complexity, when combined in all possible ways, yield an array of several different possible alternative methods that may be used for demand estimation, all more or less acceptable in practice. This variety rides on the assumptions that (a) where needed, available computer software supports nonlinear modeling of the individual member components and (b) no premature, brittle modes of failure that would macroscopically cause a post-peak softening branch identifiable trough a negative or zero pivot in the stiffness matrix of a structure would occur over the range of calculated seismic response. 
The above assessment code builds on established computer modeling technologies for lumped systems, mostly frames, for which most commercial codes enable modeling of lumped or spread nonlinearity and detailed time history calculations. And because it calls on concepts that are general in principle, it is considered applicable and easily extendable to all types of structures, including URM buildings. However, when attempting to practically apply the above ideas to the simplest of these structures, a number of stumbling blocks may be encountered. For one, the state of the art in structural software today does not address the requirement (b) above: URM is brittle and thus, maintaining a positive definite stiffness of pier members after cracking is not possible particularly in tension-controlled modes of failure. Furthermore, most of the available commercial software packages today do not offer the option for 3-D analysis using nonlinear shell elements that are needed to model masonry wall behavior. So, accounting for nonlinearity in this class of structures is restricted to either onedimensional elements (beams, trusses, springs and gap elements) that can be used to modeling secondary elements (such as timber beams in diaphragms and roof trusses) or points of contact (such as unilateral contact at the point of embedment of a timber beam in a masonry wall using gap elements, contact between foundation masonry with the surrounding soil using springs with asymmetric properties, etc.). Last, most commercial software packages today do not offer complete options for dynamic response estimations, except for combinations of modal response maxima (which, being based on the principle of superposition, precludes the option for even considering secondary sources of nonlinearity). An added difficulty emanates from the distributed character of URM structures. As the number of modes generated is proportional to the total number of degrees of freedom in the structure, there is no clearly prevelant "first" or "fundamental" mode. The mode with the highest period is oftentimes associated with vibration of a single secondary component (such as a diaphragm timber beam), with insignificant ratio of mobilized mass. Previous studies by the authors and co-workers [2, 3] have illustrated that in some cases with flexible diaphragms, several hundreds of modes need to be included in the calculation just so as to mobilize $70 \%$ of the total mass in lateral translation. This numerical circumstance in practice nullifies the so called equivalent single degree of freedom representation of the structure, which, combined with the pushover analysis methods, forms the backbone of modern code methods for seismic assessment and design (see EC8-I, Appendix B [4]).

Special - research-oriented software may be used instead to conduct detailed time history analysis of URM structures (e.g. ABAQUS, DIANA, etc.); the effort required is disproportionately higher than the degree of confidence in the actual values of the input parameters concerning both the materials and the description of the seismic hazard, violating a fundamental principle of modern simulation. Therefore an urgent research need is facing the earthquake engineering community, regarding formulation of a simple framework for seismic assessment of URM structures that could also be used to guide seismic retrofit. This objective is the motivating interest in the present paper: a seismic assessment method that produces results of equivalent accuracy to detailed time-history dynamic analysis-based assessment procedures, yet requires significantly shorter computational time, is presented, specifically tailored to the morphology and particularities of older URM structures. Here, the seismic hazard is specified in its spectral format (total acceleration and relative displacement) so as to render the methodology compatible to design code formats. To deal with the uncertainty associated with a dependable estimation of the structural period, all structures up to two storey heights (the most common sample of the URM heritage building population in southern Europe) are evaluated at the end of the constant acceleration range of the spectral plateau. The principles of generalized single degree of freedom representation of complex distributed systems are used to convert the structure to an ESDOF system consistent with the established code procedures - the 
fundamental response shape is almost a heuristic approximation of the fundamental translational mode of vibration, used as a tool for a global to local transformation of displacement demands thereby identifying locations of anticipated damage. The behavior factor $\mathrm{q}$ is obtained from the peak ratio of demand to supply in terms of out-of-plane moments of the free standing walls of the structure and is subsequently used to modify spectral displacement estimates through pertinent $\mathrm{q}-\mu-\mathrm{T}$ relationships.

Application of the proposed method provides information about the condition assessment of the structure and the anticipated damage localization at the state of the building's maximum seismic response, based on the translational modal characteristics of the building. As illustrated in the presented example analyses of two neoclassical buildings of the late $19^{\text {th }}$ Century the proposed method can lead to equally dependable estimates as the results of complicated and time-consuming dynamic time-history analysis.

\section{PROCEDURE FOR SEISMIC ASSESSMENT OF HISTORICAL BUILDINGS BASED ON THEIR FUNDAMENTAL MODE SHAPE}

The significance of the fundamental response shape as a diagnostic tool for seismic assessment of existing structures has been illustrated in recent studies in the field of seismic assessment [5 - 7]. The fundamental translational shape is a compound property that conveys information about the tendency for localization of deformation demand in the structure. Therefore, the fundamental shape of a structure can be used to identify likely points of concentration of anticipated damage through the distribution of relative drift, while at the same time identifying lack of stiffness and the relative significance of possible mass or stiffness discontinuities (Fig. 2).
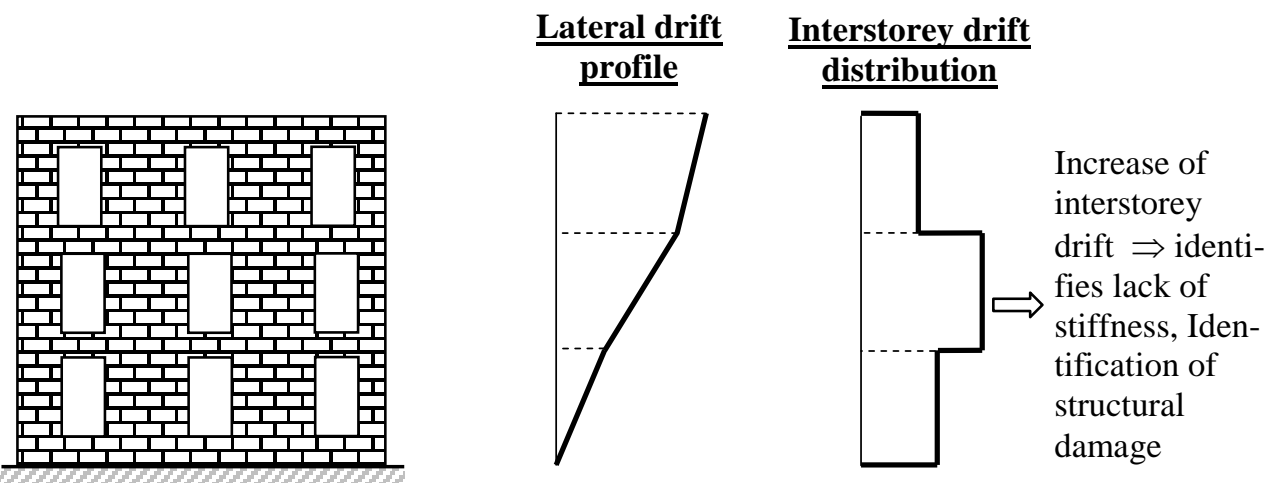

Figure 2: Use of the building's deformed shape in the identification of developed structural damage points.

Furthermore, the fundamental response shape of any structure with established diaphragm action at the floor levels has been proven to correlate very well with the structure's displacement profile at the state of maximum roof displacement $[5,8]$. This conclusion was derived from the results of parametric dynamic analyses of several R.C. building models, both simplified and detailed, accounting for different types of geometric configuration that were subjected to ground accelerations of different characteristics. It was shown that the deformed shape of any multi-storey structure in the presence of diaphragms resembles the fundamental mode shape (i.e. the mode shape that mobilizes the greatest percentage of its total mass) at the point of maximum roof displacement, especially when the period of a building's fundamental mode is in the range of the predominant period of the seismic vibration. This conclusion was further extended to nonlinear systems, where the fundamental shape refers to the eigen-mode associated with the secant stiffness matrix at the instant of peak response. 
Given the fact that some floor types used in historical or heritage masonry buildings of the $19^{\text {th }}$ and $20^{\text {th }}$ Century provide adequate diaphragmatic response, the fundamental mode shape of those buildings has also been used to identify potential damage locations under earthquake; recent studies (Karantoni et al. [3], Pardalopoulos and Pantazopoulou [2], Kontari [9]) have tested application of the same concept in URM buildings with flexible diaphragms, with good success. To do so, a three-step procedure for seismic assessment of the URM historical buildings is presented, which produces results of equal accuracy as compared to complex timehistory dynamic analyses. The three steps of the proposed procedure are:

- Determination of the fundamental translational mode of the URM building: The determination of the fundamental translational mode in each of the two principal plan directions of the examined building can be accomplished by subjecting a three-dimensional finite element model of the building to a notional gravitational field in the corresponding direction of lateral translation (i.e. along the longitudinal and transverse directions of the plan geometry). In light of the fact that gravitational forces are proportional to the mass of the structure whereas the restoring forces in free vibration are equilibrating these mass-proportional inertia forces, the deflected shape of the structure obtained from this solution is thought to be the closest approximation to the translational mode of vibration since the associated natural frequency would result from the ratio of the work-equivalent inertia force and restoring force [10]. This procedure is more suitable for the determination of the fundamental translational modes of load-bearing masonry structures that are simulated using three-dimensional finite element models of spread mass area elements rather than the execution of modal analysis, as in most cases modal analyses of this type of finite element models leads to a large number of very similar translational modes with closely spaced periods, each having a small participation factor, leading to the requirement of including several modes in the calculation in order to mobilize the structural mass. On the contrary, the building's fundamental translational modes which are determined with the use of a notional gravitational field in the direction of lateral translation correspond to a mass participation factor in the direction of action, in the range of $90 \%$ or more [2]. Taking into consideration the brittle response of URM, which cannot secure a positive definite stiffness of pier members after cracking, the examined building can be simulated as a linear finite element model, with localized points of non-linear response (i.e. at points of contact or in modeling secondary elements).

- Calculation of the seismic response of the building at the state of its maximum seismic response: Based on the postulated proportionality between the fundamental translational mode of a structure and the corresponding deformed shape at the state of its maximum seismic response [5, 8], the building's maximum seismic response can be determined using the spectrum seismic demand that is applicable at the site [4]. For this reason, the amplification factor $f_{i}$ is introduced:

$$
f_{i}=S_{d, i}(T) / U_{R o o f, i}
$$

where, $S_{d, i}(T)$ is the seismic demand in plan direction $i(x$, or $y)$ in terms of spectral relative displacement and $U_{R o o f, i}$ is the horizontal translation at the roof level of the building in the corresponding direction, $i$, as calculated in the previous step of the proposed procedure. According to this procedure, maximum seismic response of the examined URM historical structure in terms of developed deformations along its structural system can be determined by multiplying the building's fundamental translational modes with the amplification factor $f_{i}$. Furthermore, $f_{i}$ allows the determination of the developed forces/stresses along the building's structural system at the same time segment of the earthquake excitation; the developed forces/stresses at the state of the building's maximum seismic response are equal to the corresponding value of 
the building's fundamental mode, multiplied by $f_{i}$. The building's fundamental period, $T$, by which $S_{d, i}(T)$ can be calculated according to EC8-I [4], as:

$$
T=\mathrm{C}_{\mathrm{t}} \cdot H^{3 / 4}
$$

In Eq. (2), $H$ is the total building height, in $\mathrm{m}$, measured from the level of foundation or the level of rigid basement and $C_{t}$ a constant given by the relationship:

$$
C_{t}=0,075 / \sqrt{A_{c}} \leq 0,05
$$

The upper level in Eq. (2.b) refers to URM buildings with flexible diaphragms (Karantoni and Pantazopoulou [3]). $A_{c}$ depends on the total area of load-bearing walls in the ground floor of the building (in $\mathrm{m}^{2}$ ) and is calculated from:

$$
A_{c}=\Sigma\left[A_{i} \cdot\left(0,2+\left(l_{w i} / H\right)\right)^{2}\right]
$$

$A_{i}$ is the active cross section of the $i$-th wall in the direction of seismic action considered in $\mathrm{m}^{2}$, and $l_{w i}$ is the length of the $i$-th wall in the direction of seismic action, in $\mathrm{m}$.

- Determination of local seismic demand and application of acceptance criteria: Bearing capacity in URM historical structures can be best identified by the amount of deformation occurring in the various components of the structures. The use of deformation demand for the purpose of seismic assessment of structures is more meaningful than force demand estimation - based on the equal displacement rule, elastic displacement demands are close to the inelastic ones, whereas forces in the nonlinear analysis are vastly different from the elastic values. Performance criteria are also specified in terms of relative drift ratio - the drift capacity may refer either to URM piers deforming laterally so that drift refers to the relative deviation of the pier ends from vertical, or alternatively, it may refer to URM facades deviating from their horizontal initial orientation. These parameters, are referred to as relative drift ratios in height and in plan of the examined building, $\theta_{\text {height }}$ and $\theta_{\text {plan }}$ respectively, defined in case of $\theta_{\text {height }}$ as the horizontal displacement difference that occurs between the top and the bottom of each of the vertical structural elements (i.e. piers and walls) at each storey of the building, divided by their vertical length, whereas $\theta_{\text {plan }}$ is defined as the relative lateral displacement of any two points of the plan perimeter divided by their horizontal distance. In this regard, the most meaningful pair of points to be used at the crest of the building (or at the floor levels) is the point of peak outwards deflection in the wall orthogonal to the earthquake action, and the point at the corners where transverse walls are intersected by walls parallel to the earthquake.

Deformation measures calculated above can be used to determine the performance level (characterization of damage level) attained by the structure in response to the design earthquake. Cracking rotations (drift ratios) in masonry elements are in the order of $0.15 \%$, but the available ductility capacity varies depending on the type and reinforcement (e.g. timber lacing) of the URM walls. In well-constructed masonry a drift capacity of $0.5 \%$ (drift ductility of 3.5) may be attainable, and timber-laced or adobe masonries even larger values may be well depended upon. But plain unreinforced masonry without timber lacing is unlikely to be able to support rotation or drift ductilities in excess of 2 (a drift ratio of $0.3 \%$ ).

\section{EXAMPLE ANALYSES OF TWO NEOCLASSICAL BUILDINGS OF THE $18^{\text {TH }}$ CENTURY}

To investigate the accuracy of the proposed analysis procedure as compared to the corresponding results obtained from detailed time-history dynamic analysis, the proposed analysis method has been performed in three-dimensional finite element models of two neoclassical 
building located in the center of the city of Thessaloniki, Greece. The buildings were constructed in the end of the $19^{\text {th }}$ Century, according to the designs of Ernst Ziller, in order to house at that time the Hellenic high school and the Hellenic consulate of Thessaloniki, respectively. Both buildings operated continuously for more than 80 years until June of 1978, when both buildings suffered damages by a strong earthquake of $6.5 M_{w}$ that struck the city of Thessaloniki, with its epicenter located about $40 \mathrm{~km}$ North-East of Thessaloniki, in the Volvi lake region.

\subsection{Description of the examined buildings}

The Hellenic High School of Thessaloniki is a two-storey building with a basement and a timber-framed roof (Fig. 3(a)), constructed in 1893 according to the designs of Ernst Ziller, as those modified of the architects Kabanakis and Kokkinakis; the project was financed by Andreas Sygros and the Hellenic community of Thessaloniki [11].

The building has a $20.83 \mathrm{~m} \times 16.05 \mathrm{~m}$ plan, symmetrical with respect to a main corridor that is spanning from the northern side of the building to the southern, whereas the external building height, from ground level to the roof top, is $14.20 \mathrm{~m}$. The first storey comprises six rooms, symmetrically located on both sides of the storey's corridor (Fig.3(c)). The second storey was originally constructed to have four halls, one big hall on each side of the corridor spanning from the front view of the building (north view) to the south and two smaller ones in the southern part of the plan. Over the years, the two big halls were divided, the eastern one with the addition of a $0.15 \mathrm{~m}$ thick brick wall and the western one with the addition of a wooden panel (Fig. 3(d)). The basement comprises five rooms that were used as storage rooms and sanitary facilities, after the addition of miscellaneous infill brick walls (Fig. 3(b)). Floors were connected with a wooden stair in the southern part of the main corridor.

The walls of the basement are made of stone, having a thickness equal to $0.75 \mathrm{~m}$ in the perimeter of the building and $0.65 \mathrm{~m}$ in the inner plan. Walls of the first and the second storey were built of solid brick. Perimeter walls have $0.50 \mathrm{~m}$ width, whereas internal walls were $0.40 \mathrm{~m}$ thick. Floors of the first and the second storey were made of double T iron beams having a $60 \mathrm{~mm} \times 180 \mathrm{~mm}$ cross section, spaced at $0.70 \mathrm{~m}$ along the small sides of the rooms and the corridors (i.e. having an E-W orientation over the building's corridors and a N-S orientation over the building's halls), whereas brick-arches spanning in the transverse direction between successive iron beams were encased between the upper and lower flanges of the double $\mathrm{T}$ beams. The total thickness of building's floors (including the finishing) is $0.33 \mathrm{~m}$ at the location of the iron beams and $0.25 \mathrm{~m}$ at the highest point of the arches. The last storey is covered by a roof made of timber trusses spanning in the east to west direction of the building.

The building had operated continuously as a school from its construction until the June of 1978, when it suffered moderate damages mainly in the area of connection of the roof with the $2^{\text {nd }}$ storey walls and operated again as a school in 1985, after the restoration of the damages. 


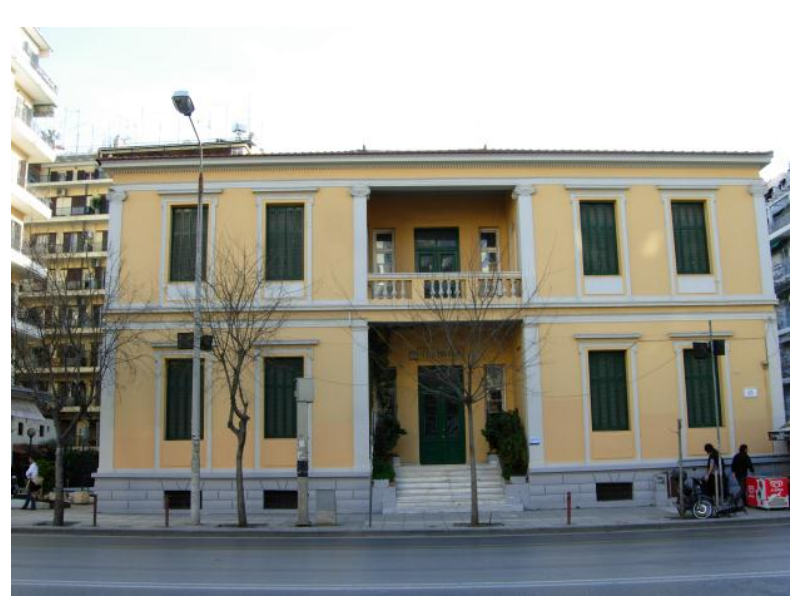

(a)

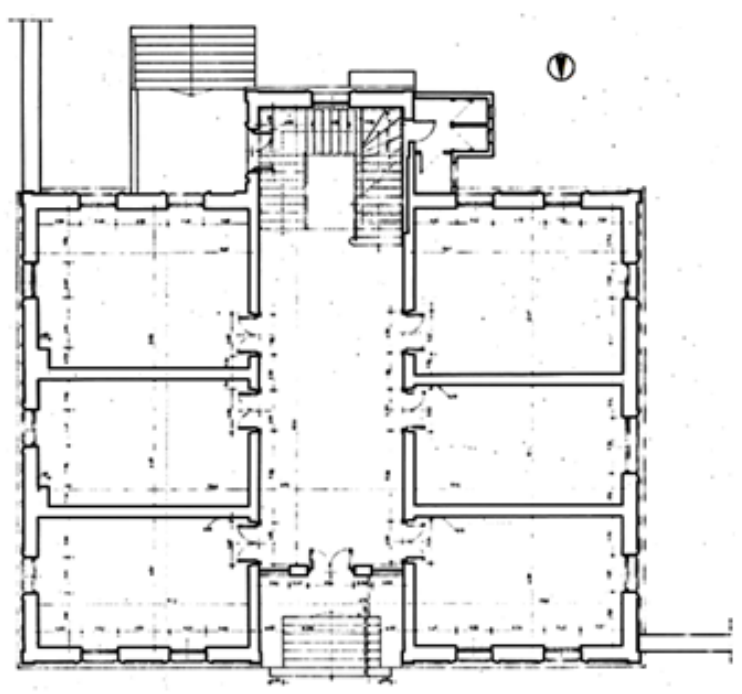

(c)

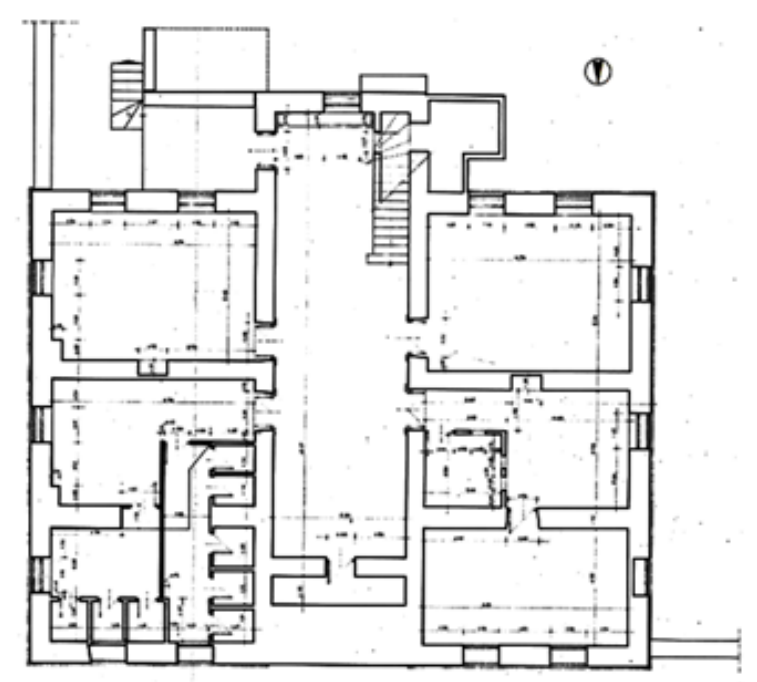

(b)

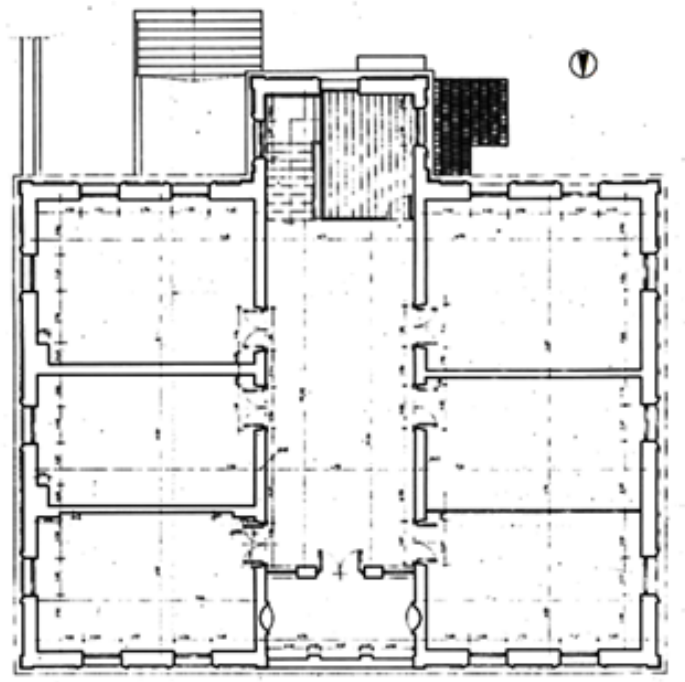

(d)

Figure 3: The Hellenic High School of Thessaloniki: (a) North view, (b-d) plan views of the building's basement, $1^{\text {st }}$ and $2^{\text {nd }}$ storey, respectively [12].

The Hellenic Consulate of Thessaloniki is also a two-storey building with a basement and a roof (Fig. 4(a)), constructed in 1898 in the center of Thessaloniki. The building was also made according with the designs of Ernst Ziller and again, it was financed by Andreas Sygros $[12,13]$, to house the consulate of Greece during the Ottoman occupation of the city of Thessaloniki, whereas after the liberation of Thessaloniki in 1912 the building had operated as a primary school until 1978, when it suffered heavy damages from the earthquake.

The building has a $15.20 \mathrm{~m} \times 19.00 \mathrm{~m}$ orthogonal plan, whereas the external building height, including the roof, is $14.45 \mathrm{~m}$. The first storey (Fig. 4(c)) is of total area of $288.80 \mathrm{~m}^{2}$ and comprises five rooms, located in both sides of the storey's corridor. Communication between the first storey and the basement is achieved via a stairwell located at the west end of the $1^{\text {st }}$ storey's corridor, whereas a second stairwell located at the north-eastern corner of the building leads to the second storey of the building. The second storey of the building (Fig. 4(d)) has six rooms of various sizes, located on both sides of the storey's corridor. The basement comprises four rooms at the north side of the main corridor that were used as storage rooms and a large room along the building's southern side (Fig. 4b)). 
The walls of the basement are made of stone, having a thickness equal to $0.65 \mathrm{~m}$ in the perimeter of the building and $0.55 \mathrm{~m}$ in the inner plan. Walls of the first and the second storey were built of solid brick. Perimeter walls are $0.55 \mathrm{~m}$ thick, whereas internal walls' thickness varies from $0.10 \mathrm{~m}$ to $0.45 \mathrm{~m}$. Floors of the first and the second storey were made of double $\mathrm{T}$ iron beams, whereas brick-arches spanning in the transverse direction between successive iron beams were encased between the upper and lower flanges of the double $\mathrm{T}$ beams. The last storey is covered by a roof made of timber trusses spanning in the north to south direction of the building.

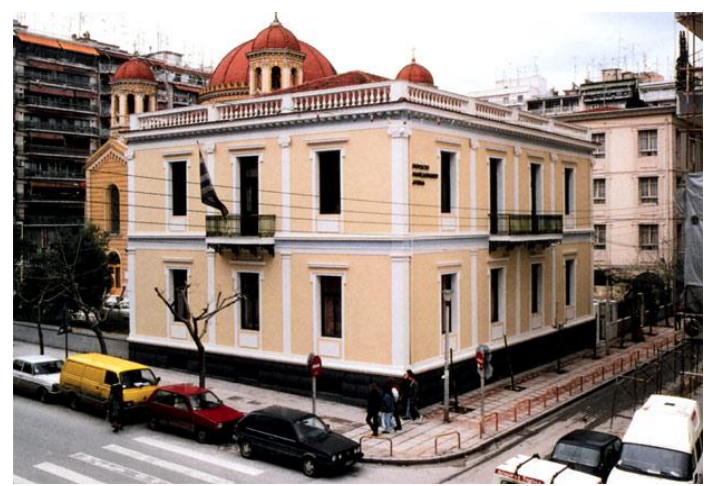

(a)

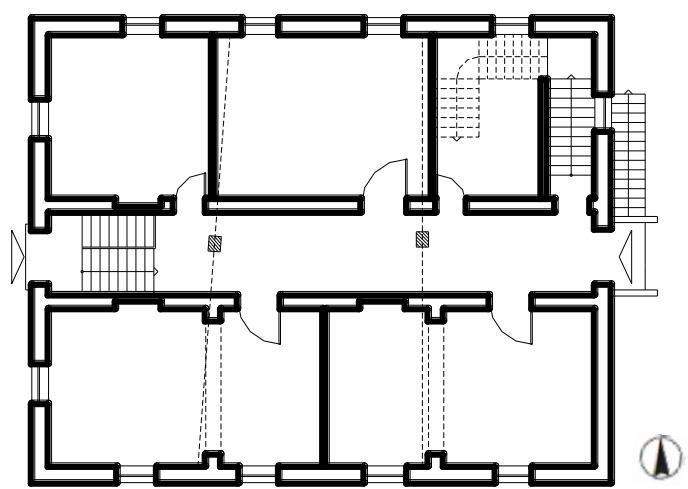

(c)

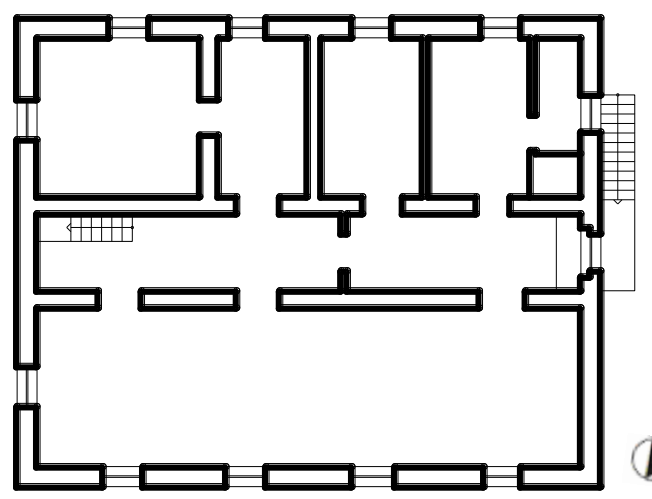

(b)

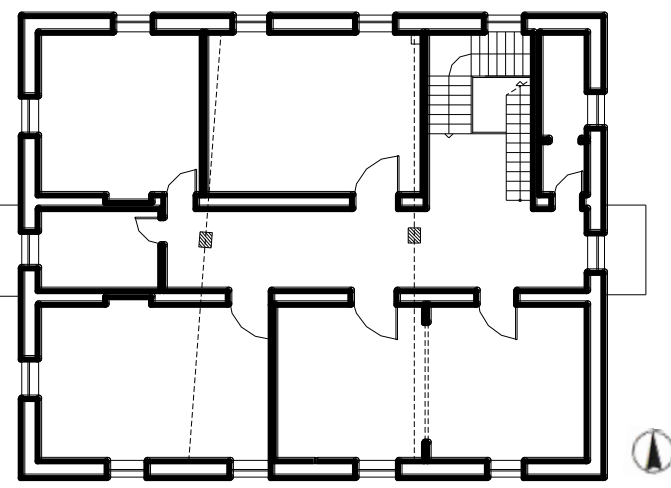

(d)

Figure 4: The Hellenic High School of Thessaloniki: (a) North-West corner of the building, (b-d) plan views of the building's basement, $1^{\text {st }}$ and $2^{\text {nd }}$ storey, respectively.

\subsection{Modeling and analyses of the two examined buildings}

In order to investigate the seismic response of the two buildings during the 1978 earthquake, three-dimensional finite models were produced (Fig. 5) using a finite element analysis program [13]. In all building models walls were idealized using four-node shell elements, capable of supporting forces and moments ( 6 d.o.f. per node), whereas floors were simulated using linear elements for the iron beams and shell elements to represent the brick arches spanning between steel beams. Linear elements were used at the roof level, accounting for the horizontal timber beams of the roof trusses. In all models, the response of the shell and the linear elements was considered elastic. The modulus of elasticity of stone and bricks was considered 1000 times the value of the corresponding compressive strength, $f_{k}$; this variable was taken equal to the following: (a) in the case of the Hellenic High School for stone $f_{k}=5.5 \mathrm{MPa}$, for solid bricks $f_{k}=4.0 \mathrm{MPa}$ and for voided bricks $f_{k}=1.5 \mathrm{MPa}$, whereas in the case (b) of the Hellenic Consulate, for stone $f_{k}=6.3 \mathrm{MPa}$ and for solid bricks $f_{k}=5.2 \mathrm{MPa}$. In the case of 
frame (iron and timber) elements, the modulus of elasticity was taken equal to $150 \mathrm{GPa}$ for the iron beams, $10 \mathrm{GPa}$ for timber in the longitudinal direction of the beams and 1GPa in the other two sectional directions. In all cases self weight of the building was calculated according to the material density; for stone $28.5 \mathrm{kN} / \mathrm{m}^{3}$, for solid bricks $18 \mathrm{kN} / \mathrm{m}^{3}$ and for voided bricks $14 \mathrm{kN} / \mathrm{m}^{3}$. A roof weight equal to $1.5 \mathrm{kN} / \mathrm{m}^{2}$ was assumed, uniformly distributed along the linear elements of the roof trusses according to their tributary area. Service loads were considered equal to $2.50 \mathrm{kN} / \mathrm{m}^{2}$ for the roof and $3.50 \mathrm{kN} / \mathrm{m}^{2}$ for the floors of both buildings.
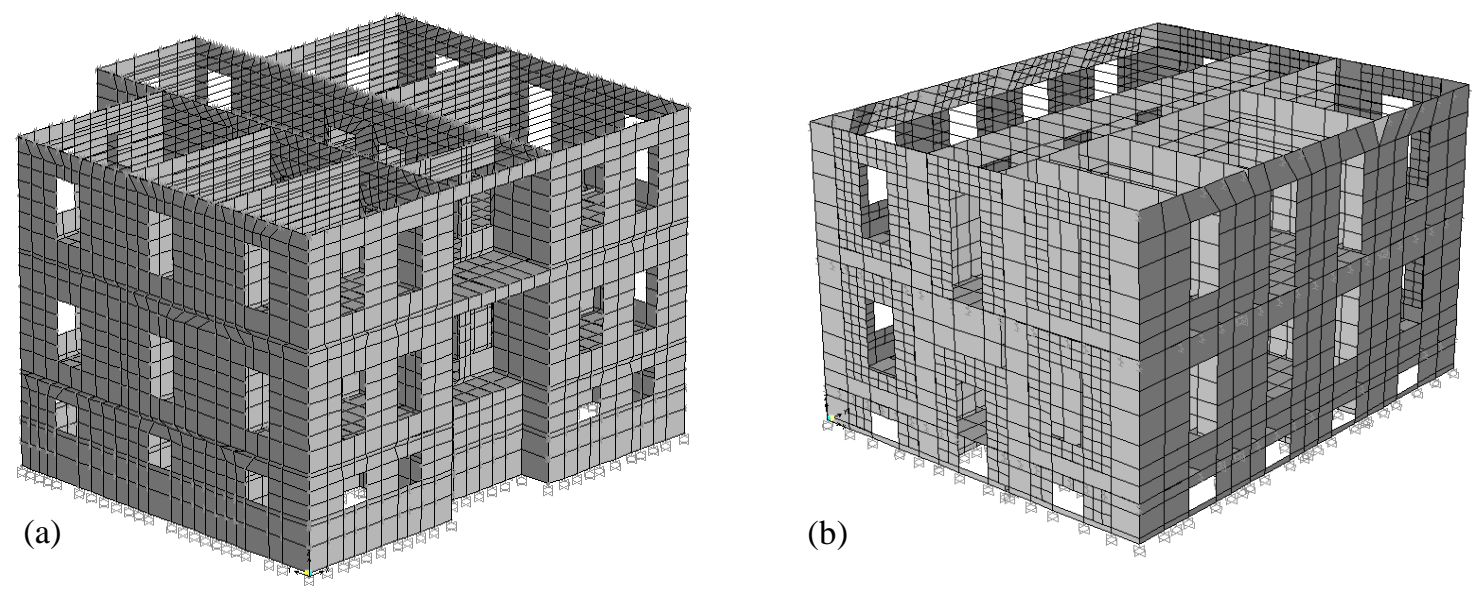

Figure 5: Three-dimensional finite element models of (a) the Hellenic High School and (b) the Hellenic Consulate of Thessaloniki.

For each building two building models were produced, referred to as $A$ and $B$, in order to investigate the influence of modeling assumptions for the various mechanisms that develop in the structural system of the $19^{\text {th }}$ and $20^{\text {th }}$ Century load-bearing URM piers owing to the construction practices and the influence these have on the overall seismic response of the buildings. In both cases parameters of investigation were the developed mechanisms at the floors and the roof. In finite element models $A$ the linear elements that were used to simulate the floors' iron beams were considered fixed at their ends to the shell elements accounting for the constraint provided by the infill brick arches. Fixed connections were also considered at the ends of timber beams of the roof trusses to the wall elements. In finite element models $B$, gap elements were added between the nodes of the shell elements that represented the brick arches and the corresponding nodes of the iron beams, replacing the fixity condition for the same contact detail in models $A$ (Fig. 6(a)). Thus, gap elements were intended to model the separation between the brick arches and the iron beams when in tension whereas they were considered rigid in compression (perfect contact). Also added in models $B$ were springs between the nodes of the wall elements and the timber beams over the wall, which were meant to account for friction between the wall and the timber beams. Spring-response was described by a multilinear force-displacement relationship (Fig. 6(b)) that was calculated according with the development capacity over the beams' contact surfaces when accounting for friction with the building walls. 

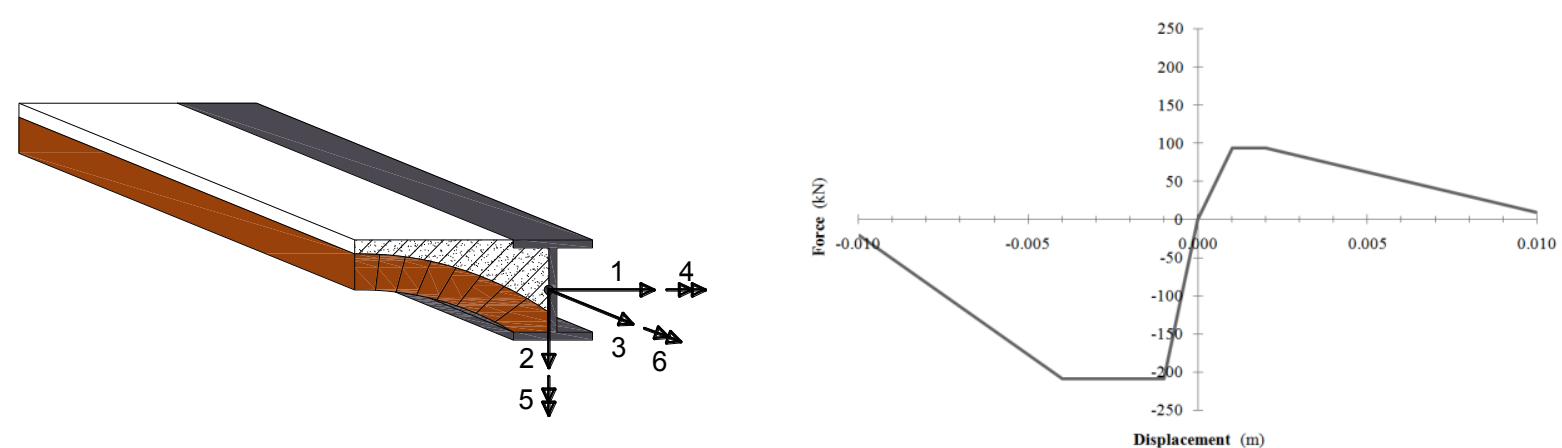

Figure 6: (a) Simulation of the connection of iron beams and infill brick arches at the buildings' floors by the addition of gap elements functioning in degree of freedom 1 (b) Force-displacement relationship used in the friction springs that connect the timber beams with the walls of the second storey.

In order to investigate the accuracy of the simulation for the two buildings, all finite element models were subjected to time-history dynamic analyses based on the 1978 Thessaloniki earthquake ground accelerations that were recorded at locations near the buildings site [14]. Figure 7 illustrates the E-W (blue color) and N-S (red color) components of the recorded ground accelerations, as well as the corresponding elastic response spectra calculated for the case of 5\% damping. Masses considered in the time-history analyses were automatically calculated by the program, by multiplying each element (shell or linear) volume by their respective density.
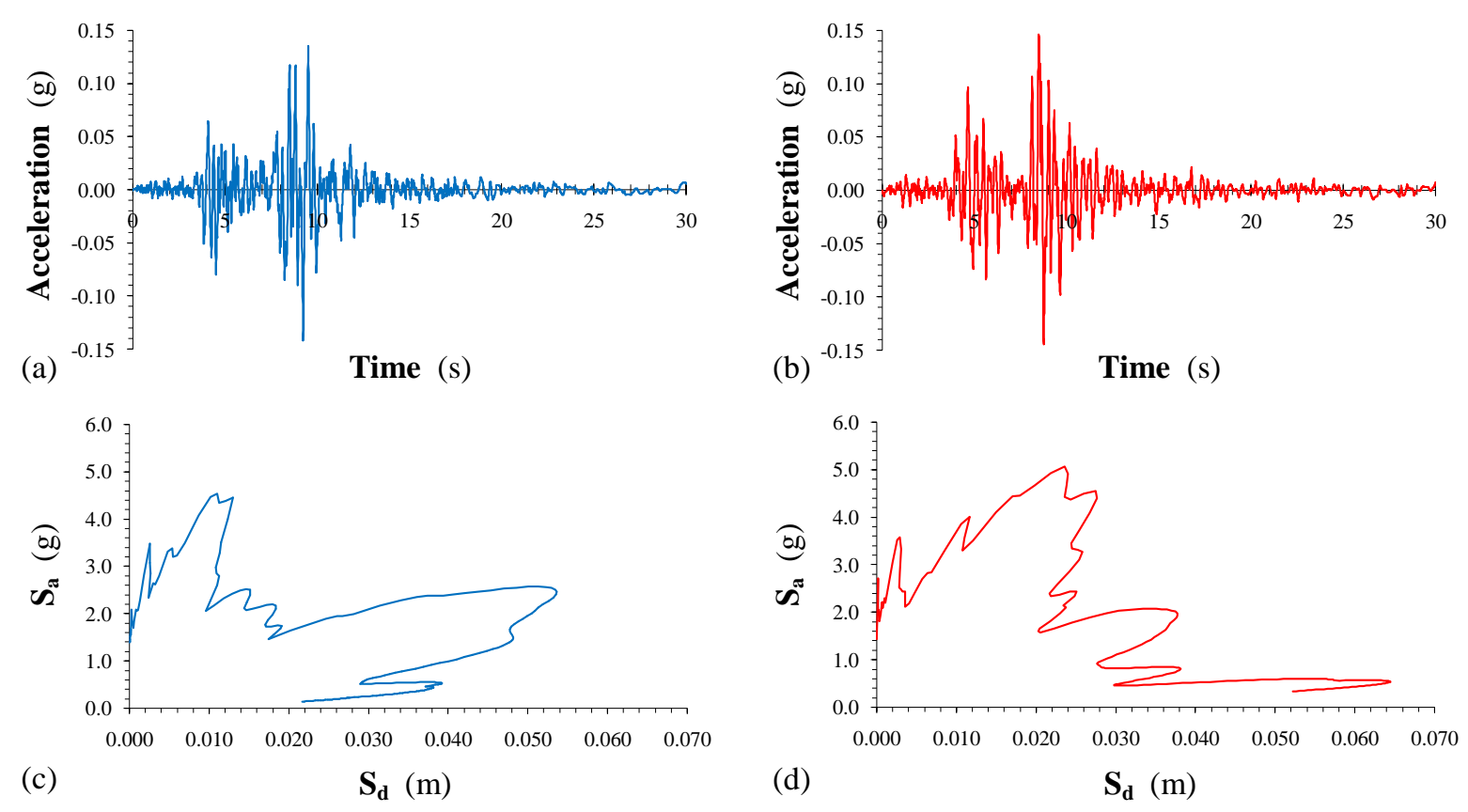

Figure 7: 1978 Thessaloniki earthquake: (a, b) Recorded ground accelerations in E-W (blue color) and N-S (red color) directions at the center of Thessaloniki, Greece, (c, d) Elastic response spectra of the corresponding earthquake components calculated for $5 \%$ damping (ADRS format).

From the examination of the dynamic response of models' $A$ and $B$ of each building interesting conclusions have derived concerning the significance of simulation of the special mechanisms that develop in the $19^{\text {th }}$ and $20^{\text {th }}$ Century load-bearing masonry buildings due to the construction practices followed at that era. From the analyses results it is evident that the simulation of the separation between the brick arches and the iron beams when tension stress- 
es develop in the floor diaphragms (with the aid of gap elements), results in significant reduction in the developed stresses and deformations throughout the buildings' structural system. Figure 8 illustrates the shear reactions acting on each one of the two principal plan directions of the Hellenic High School (i.e. in the E-W and the N-S directions) during the earthquake excitation. As illustrated in Fig. 8, in the time range of the building's maximum seismic response the base shear in model $B$ are reduced by $22 \%$ in $\mathrm{E}-\mathrm{W}$ and by $18 \%$ in N-S direction, respectively, as compared to the corresponding values developed in model $A$ for the same time range. Also reduced in building model $B$ were the developed horizontal displacements along the buildings' height at the time of peak response by an average of $25 \%$ and $21 \%$ in E$\mathrm{W}$ and N-S directions, as compared with the same measures for model $A$ (Fig. 9). Similar reductions in the developed base shear and horizontal displacements at the time of building's response were also seen between models A and B of the Hellenic Consulate.
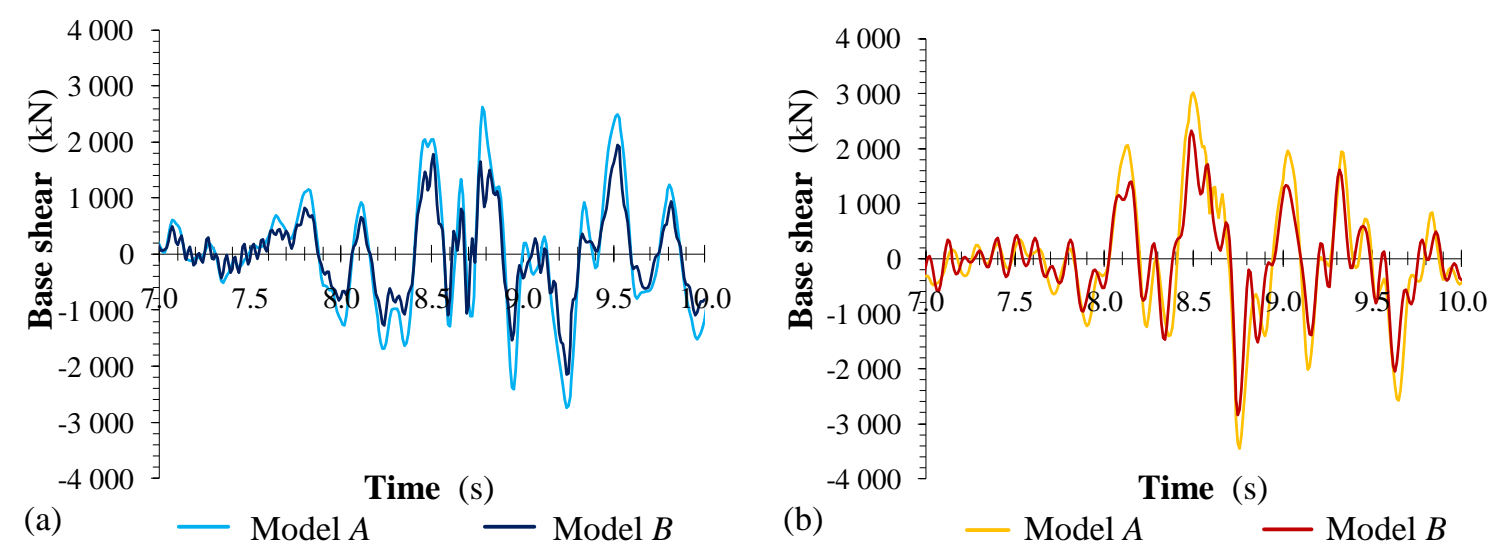

Figure 8: Time-history of base shear of models $A$ and $B$ of the Hellenic High School (a) in E-W and (b) in N-S directions.
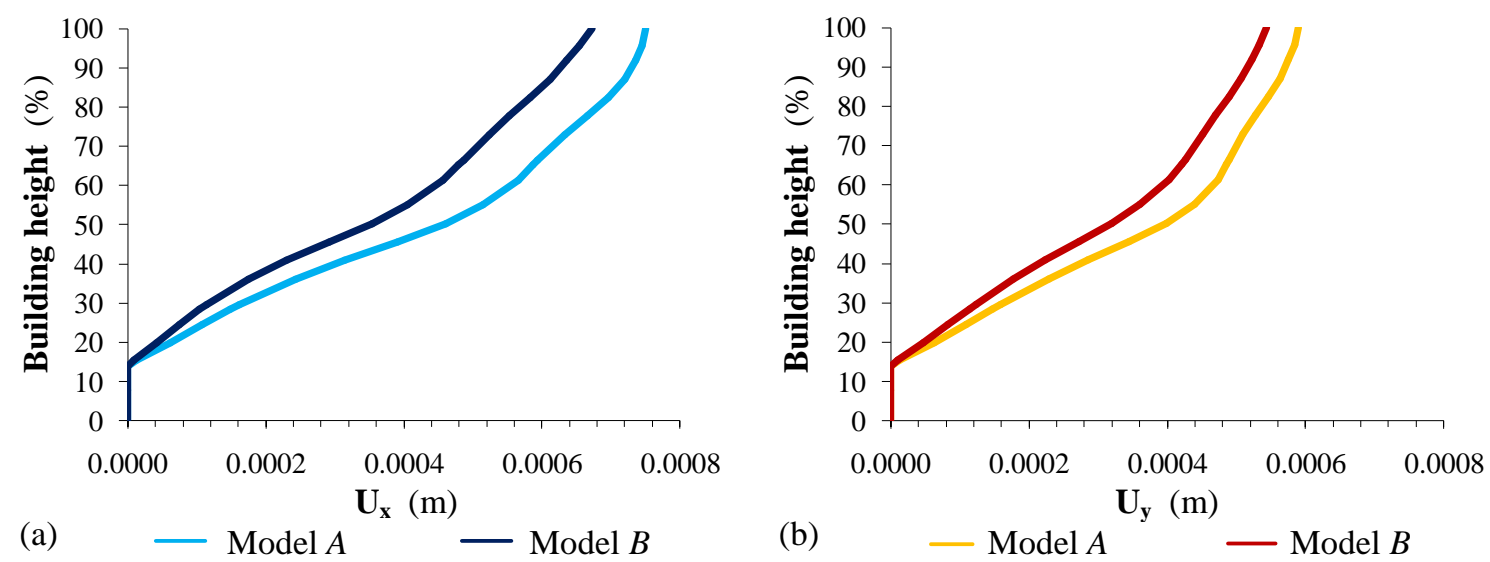

Figure 9: Deformed shape of the North-East corner axis of models $A$ and $B$ for the Hellenic High School at the time of peak dynamic response (a) in E-W and (b) in N-S directions.

Also tested using models $B$ of the two neoclassical buildings was the accuracy of the results that derive from the application of the proposed analytical method for seismic assessment of historical buildings, as compared with the corresponding results at the time of peak response obtained from time-history dynamic analysis. Figure 10 plots deformed shapes obtained for both buildings by subjecting each structure to a uniform uniform horizontal acceleration (i.e. a static pushover procedure where inertia forces proportional to the self-weight is applied pointwise throughout the nodes of the F.E. mesh). Also shown, for the sake of com- 
parison, are the corresponding shapes at peak building top displacement response, obtained from dynamic time history analyses as shown in Fig. 9. Clearly, correlation of the results between the two procedures is excellent. Also evident is the proportionality of the results that derive from the two procedures in terms of the developed stress patterns along the buildings' structural systems, which is presented in the case of the north view of the Hellenic Consulate in Fig. 11.

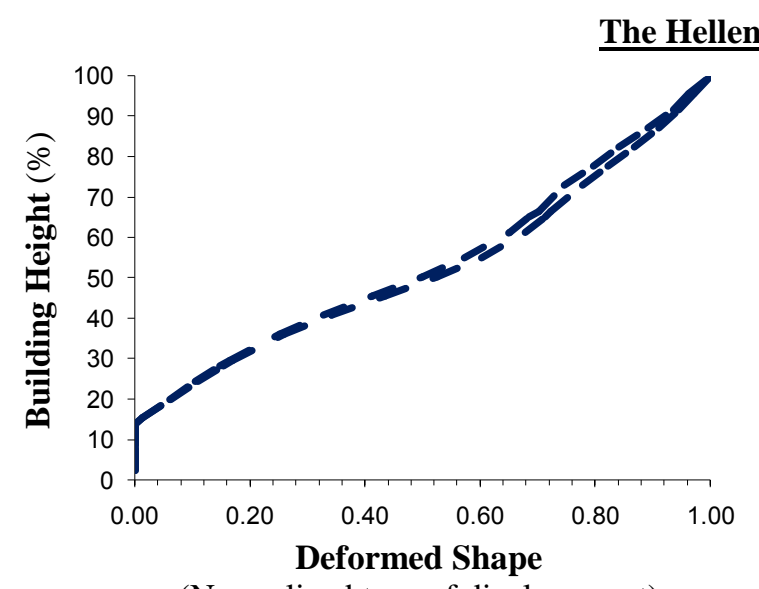

(Normalized to roof displacement)

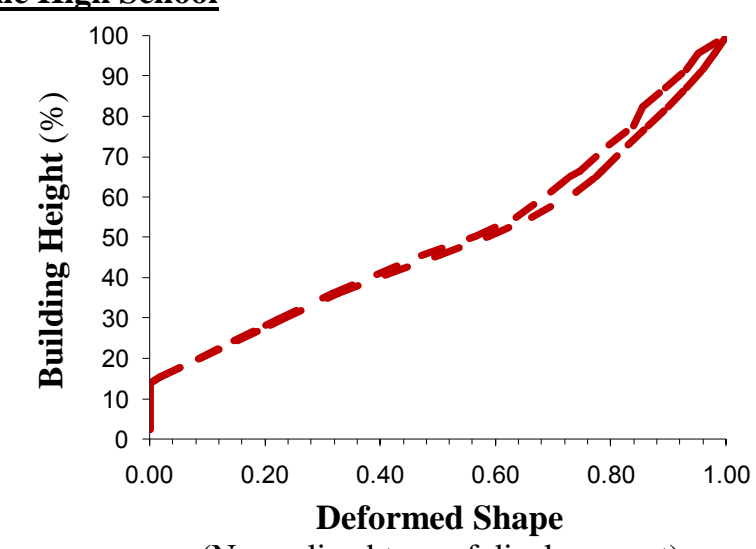

(Normalized to roof displacement)

$\underline{\text { The Hellenic Consulate }}$

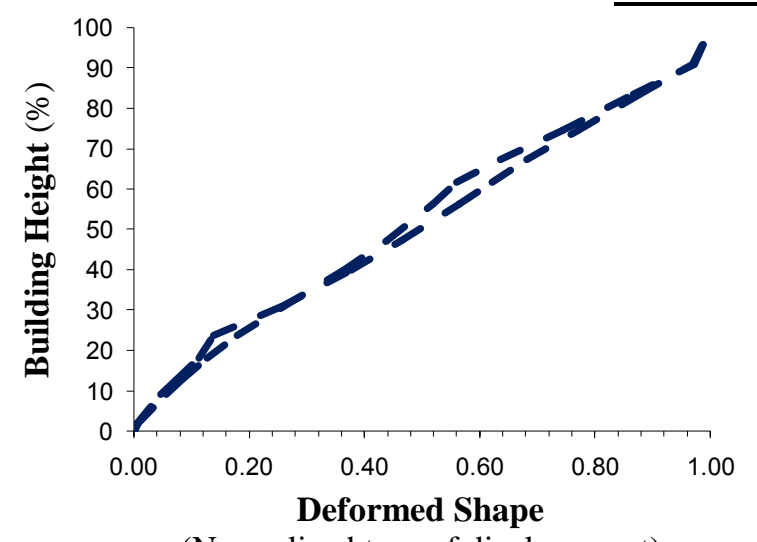

(Normalized to roof displacement)

$$
\begin{aligned}
& \text { Max. Seismic } \quad \ldots \text { Pushover response } \\
& \text { Response }
\end{aligned}
$$

(a)

Figure 10: Comparison between the deformed shape of the North-East corner axis of the two buildings at the state of peak seismic response and their estimated translational mode: (a) E-W direction, (b) N-S direction. 


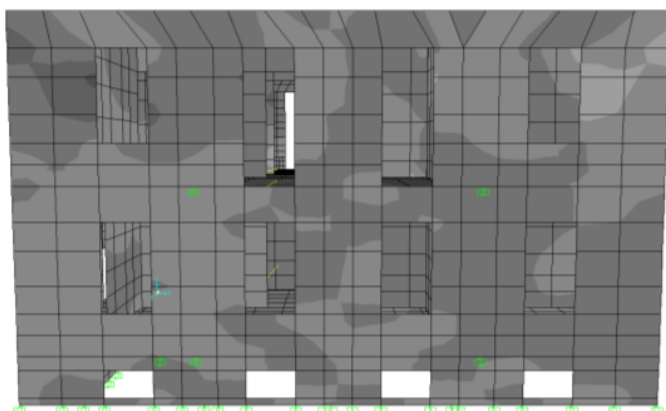

(a)

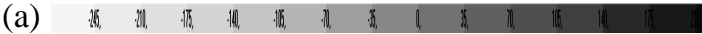

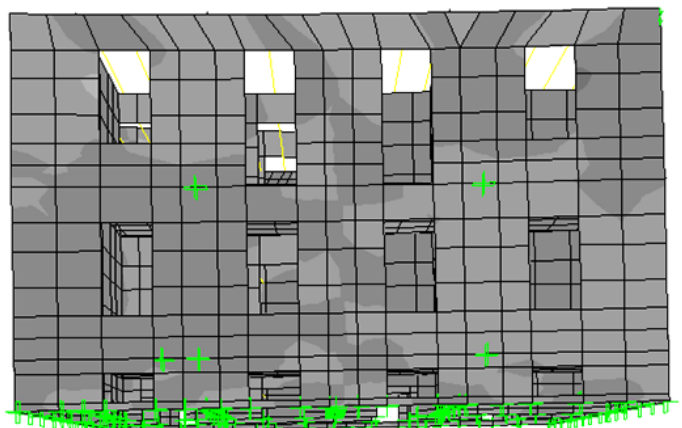

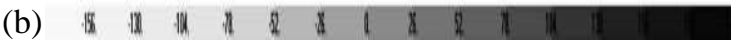

Figure 11: Developed patterns of shear stresses on the north view of the Hellenic Consulate (a) at the time of the building's maximum seismic response according to time-history dynamic analysis and (b) according to static analysis of the building with lateral loading proportional to the building's mass distribution.

Seismic assessment of the examined buildings was performed by the examination of the values of $\theta_{\text {height }}$ and $\theta_{\text {plan }}$ at each storey of the buildings. Presenting the application of the proposed assessment procedure for the case of the Hellenic High School, the building's spectral relative displacements in E-W and N-S plan directions, $S_{d, E-W}$ and $S_{d, N-S}$ respectively, were calculated from the elastic response spectra of the corresponding earthquake components (Fig. $7 \mathrm{c}-7 \mathrm{~d}$ ) according to the periods of the fundamental translational modes of the building in the corresponding directions $\left(T_{E-W}=0.303 \mathrm{sec}, T_{N-S}=0.262 \mathrm{sec}\right.$; Eq. 2$)$ as: $S_{d, E-W}=6.56 \mathrm{~mm}$ and $S_{d, N-S}=5.42 \mathrm{~mm}$. Note that $S_{d, E-W}$ and $S_{d, N-S}$, as calculated according to the proposed procedure, correlate very well with the average value of the horizontal roof displacements at the corresponding plan directions at the time of the building's maximum seismic response $\left(U_{\text {Roof }, E-W}=\right.$ $6.73 \mathrm{~mm}$ and $U_{R o o f, N-S}=5.54 \mathrm{~mm}$ ), as those were calculated from time-history dynamic analysis. Amplification factors in E-W and N-S plan directions, $f_{E-W}$ and $f_{N-S}$ respectively, were calculated according to $S_{d, E-W}, S_{d, N-S}$ and the average values of roof displacement in the corresponding directions derived from static analysis of the building with lateral loading proportional to its mass distribution $\left(U_{R o o f, E-W}=18.34 \mathrm{~mm}\right.$ and $U_{R o o f, N-S}=26.65 \mathrm{~mm}$, Figs. 12 \& 13), as: $f_{E-W}=6.56 / 18.34 \Rightarrow f_{E-W}=0.36$ and $f_{N-S}=5.54 / 26.65 \Rightarrow f_{N-S}=0.20$.
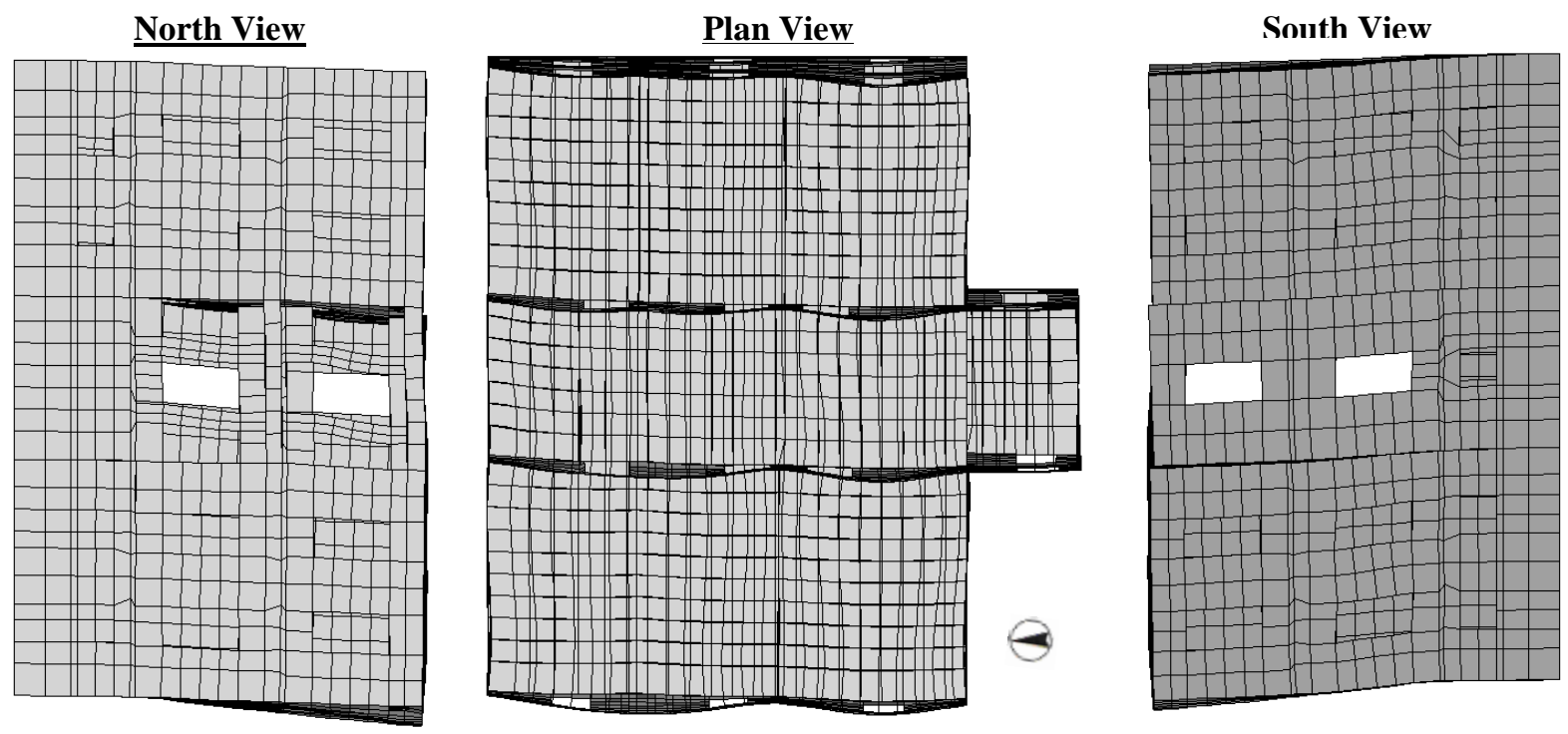

Figure 13: Deformed shape of the Hellenic High School calculated from static analysis with lateral loading proportional to the building's mass distribution in E-W direction. 

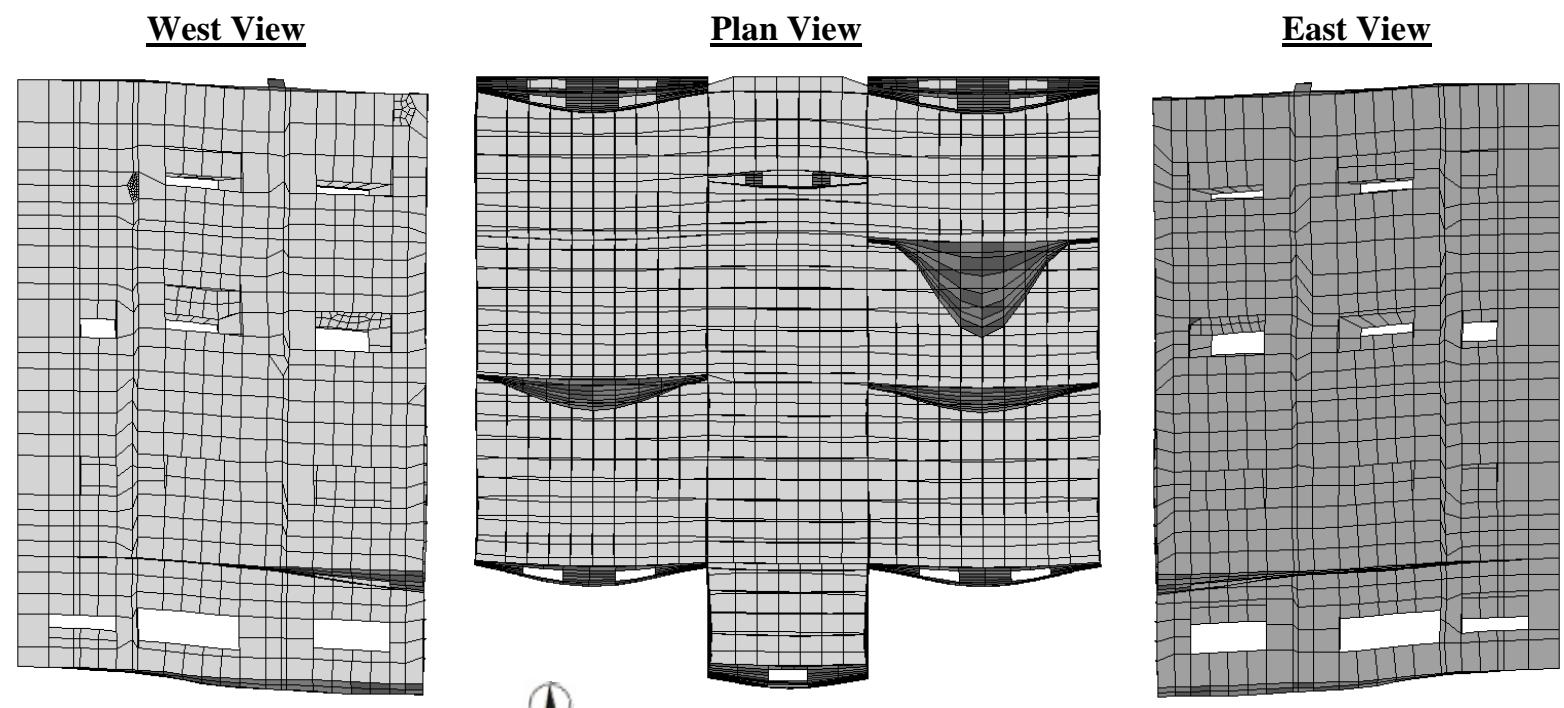

Figure 12: Deformed shape of the Hellenic High School calculated from static analysis with lateral loading proportional to the building's mass distribution in N-S direction.

Relative drift ratios in height and in plan, $\theta_{\text {height }}$ and $\theta_{\text {plan }}$ respectively, were calculated from the horizontal displacements of the structural system in E-W and N-S directions that derived from static analyses (Figs. $11 \& 12$ ) after their multiplication with the corresponding amplification factors. Table 1 presents the values of $\theta_{\text {height }}$ that were calculated at the edges of the first and the second storey, in both E-W and N-S plan directions. From the values of $\theta_{\text {height }}$ it is evident that during the 1978 Thessaloniki earthquake the walls of the first storey of the building were subjected to larger deformations than the walls of the second storey. Nevertheless, the developed deformations were not capable to cause severe damages to the building (max. value equals to drift ductility 1.2). Similar conclusions have derived from the evaluation of $\theta_{\text {plan }}$ in all storeys of the building. The only exception was the case of the infill wall that was added in the second storey some years before the 1978 earthquake in order to divide the big room at the N-E corner of the building (Fig. 12). At the time of the building's maximum seismic response during the earthquake this wall was estimated that had developed $\theta_{\text {plan }}$ $=0.817 \%$, a value equal to drift ductility 5.45 and as such it was anticipated to develop savvier damage, a conclusion that was confirmed by the examination of the actual seismic response of the building.

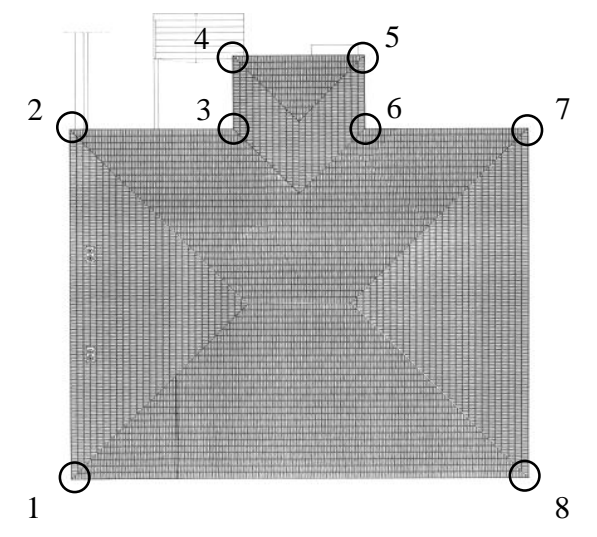

\begin{tabular}{lllll}
\hline & \multicolumn{2}{l}{$\theta_{\text {height }}-1^{\text {st }}$} & Storey $(\%)$ & \multicolumn{2}{l}{$\theta_{\text {height }}-2^{\text {nd }}$} & Storey $(\%)$ \\
Edge & E-W & N-S & E-W & N-S \\
\hline 1 & 0.07 & 0.06 & 0.06 & 0.03 \\
2 & 0.15 & 0.06 & 0.08 & 0.03 \\
3 & 0.15 & 0.07 & 0.07 & 0.03 \\
4 & 0.12 & 0.06 & 0.08 & 0.03 \\
5 & 0.12 & 0.07 & 0.08 & 0.03 \\
6 & 0.17 & 0.06 & 0.08 & 0.03 \\
7 & 0.17 & 0.06 & 0.09 & 0.03 \\
8 & 0.07 & 0.06 & 0.06 & 0.03 \\
\hline
\end{tabular}

Table 1: Values of $\theta_{\text {height }}$ at the building edges of the first and the second storey, calculated in E-W and N-S directions. 

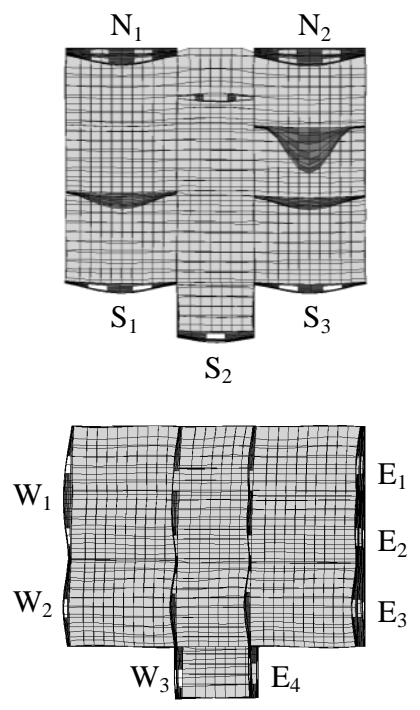

\begin{tabular}{lll}
\hline View & Point & $\theta_{\text {plan }}(\%)$ \\
\hline North & $\mathrm{N}_{1}$ & 0.18 \\
South & $\mathrm{N}_{2}$ & 0.18 \\
& $\mathrm{~S}_{1}$ & 0.17 \\
& $\mathrm{~S}_{2}$ & 0.14 \\
East & $\mathrm{S}_{3}$ & 0.17 \\
& $\mathrm{E}_{1}$ & 0.23 \\
& $\mathrm{E}_{2}$ & 0.09 \\
\multirow{3}{*}{ West } & $\mathrm{E}_{3}$ & 0.10 \\
& $\mathrm{E}_{4}$ & 0.10 \\
& $\mathrm{~W}_{1}$ & 0.23 \\
& $\mathrm{~W}_{2}$ & 0.22 \\
& $\mathrm{~W}_{3}$ & 0.10 \\
\hline
\end{tabular}

Table 2: Values of $\theta_{\text {plan }}$ of the facades of the second storey of the building at the time of its maximum seismic response.

\section{CONCLUSIONS}

Seismic assessment of load-bearing buildings of the $19^{\text {th }}$ and $20^{\text {th }}$ Century is an emerging interest for engineering community, as this class of buildings are a living part of the European modern history. Current assessment procedures, often regulated by international treaties for non-invasiveness and reversibility of the intervention combined with the practical requirements for the buildings' modern day intended reuse, are based on a vast variety of analytical methods, ranging from the use of simplified mechanical models to the use of sophisticated finite element analyses programs combined with powerful computational means. Yet, the obtained results are often of limited reliability when these assessment procedures, which are a modification of design procedures used in frame structures with ductile behavior, are applied on URM brittle piers. Therefore, an urgent research need is facing the earthquake engineering community, regarding formulation of a simple framework for seismic assessment of URM structures that could also be used to guide seismic retrofit.

In this paper an analytical method for seismic assessment of URM historical buildings, which produces results of equivalent accuracy to detailed time-history dynamic analysis based assessment procedures, yet requires significantly shorter computational time is presented. According to the proposed method, seismic demand is estimated in terms of displacement demand at the building's roof, based on the principles of generalized single degree of freedom representation of complex distributed systems, consistent with the established code procedures. Then the displacement demand is distributed through the structure following a simplified estimate of the fundamental mode of vibration in each of the two principal directions of the building in plan.

\section{REFERENCES}

[1] European Committee for Standardization (CEN), EN 1998-3 Eurocode 8: Design of Structures for Earthquake Resistance - Part 3: Assessment and Retrofitting of Buildings, Brussels, 2005. 
[2] S. J. Pardalopoulos, S. J. Pantazopoulou, Seismic Assessment of $19^{\text {th }}$ Century Heritage building Through Simulation, COMPDYN 2011 - Computational Methods in Structural Dynamics and Earthquake Engineering, M. Papadrakakis, M. Fragiadakis, V. Plevris (eds.), Corfu, 2011.

[3] F. V. Karantoni, M. Papadopoulos and S. Pantazopoulou, Criteria Guiding Seismic Assessment Strategies of Traditional Masonry Buildings, Second Conference on Smart Monitoring, Assessment and Rehabilitation of Civil Structures (2SMAR), Istanbul, 2013.

[4] European Committee for Standardization (CEN), EN 1998-1 Eurocode 8: Design of Structures for Earthquake Resistance - Part 1: General Rules, Seismic Actions and Rules for Buildings, Brussels, 2004.

[5] S. J. Pardalopoulos, Seismic Design of Natural Gas Pipeline Networks Attached in Existing and New Constructions, PhD Thesis, Demokritus University of Thrace, Xanthi, Greece, 2012.

[6] G. E. Thermou, S. J. Pantazopoulou, A. S. Elnashai, Global Interventions for Seismic Upgrading of Substandard RC Buildings, ASCE Journal of Structural Engineering, ASCE, 138(3): pp. 387-401, 2012.

[7] G. E. Thermou, S. J. Pantazopoulou, Assessment Indices for the Seismic Vulnerability of Existing R.C. Buildings, Earthquake engineering and Structural Dynamics, DOI: 10.1002/eqe.1028, Wiley InterScience, 2010.

[8] S. J. Pardalopoulos, S. J. Pantazopoulou, Spatial Displacement Patterns of R.C. Buildings Under Seismic Loads, Computational Methods in Earthquake Engineering, Computational Methods in Applied Sciences 21, M. Papadrakakis et al., Springer, pp. 123-145, 2011.

[9] M. Th. Kontari, Seismic Assessment of Neoclassical Buildings through Computer Simulation, MASc thesis, Depart. Of Civil Engineering Demokritus University of Thrace, Xanthi, Greece, 2011 (in greek).

[10] R. W. Clough, J. Penzien, Dynamics of Structures, Second Edition, MacGraw-Hill Inc., 1993.

[11] M. Papadopoulos, H. Cotta, T. Gounarido, The history of the school of the "Hellenic high school"of Thessaloniki, Municipality of Thessaloniki, Thessaloniki, Greece, 2001 (in Greek).

[12] National Service for Management of Earthquake Damages in Northern Greece (Y.A.D.B.E.), Restoration of the damages caused to the General Hellenic Consulate due to earthquake, Ministry of public works, Thessaloniki, Greece, 1979.

[13] SAP2000, Computers and Structures, Inc., University Avenue, Berkeley, California 94704, USA.

[14] ITSAK, Institute of Technical Seismology and Earthquake Resistant Structures, Thessaloniki, Greece. 